\title{
A LEAN CONSTRUCTION MATURITY MODEL FOR ORGANIZATIONS
}

\author{
Claus Nesensohn ${ }^{1}$
}

\begin{abstract}
At IGLC 2014 a Lean Construction Maturity Model (LCMM) was introduced and at IGLC 2015 its validation was presented. The LCMM offers organizations in the AEC Industry to obtain a systemic and holistic overview of their current state of LC maturity and provides them with support in their maturation. This paper intends to motivate its implementation in practice in order to test and demonstrate the whole range of benefits and implications of the LCMM. Therefore, this paper proposes a self-assessment template of the LCMM with a two-step procedure to obtain the current maturity level of any organization with regards to Lean Construction (LC). It will enable practitioners to measure the gap between where they currently are as well as develop an improvement plan to improve their LC maturity.
\end{abstract}

Keywords: Process improvement, Lean Construction Maturity, LCMM, Maturity model, Organizational assessment

\section{INTRODUCTION}

The construction industry faces the central challenge of improving its productivity and innovation (Larsson et al. 2013). In consequence, many organisations are seeking to achieve the required improvement through consequently applying the management philosophy of LC as one of the most prominent improvement approaches within the construction industry (Sage et al. 2012).

To embed LC it is necessary to measure the gap between the current state in the organisations and where they want to be in terms of Lean (Meiling et al. 2012). In this context, maturity models (MM) represents a very useful tool. It has been widely acknowledged that these models provide organisations with such an assessment of the current state and serve as guidance and support when implementing a change or improvement strategy (Pennypacker 2005; Perkins et al. 2010a; Perkins et al 2010b).

In previous works (Nesensohn 2014a, Nesensohn 2014b, Nesensohn 2015) presented the development and validation of a LC maturity assessment framework labelled Lean Construction Maturity Model (LCMM). The LCMM defines 5 levels of maturity in terms of LC, these are: uncertain, awaking, systematic, integrating, and challenging. Figure 1 illustrates the definition of each maturity level.

Focus groups are considered as an appropriate method, through the production of a consensus of a group that experienced the phenomena (Morgan and Krueger 1993). The data collection through the focus groups involved five and six LC key informants respectively and semi-structured interviews with 11 informants.

Semi-structured interviews were adopted to strengthen the validity of the data from the focus groups (Smithson 2008).

1 CEO and founder, Refine Projects AG, Schelmenwasenstraße 34, 70567 Stuttgart Germany, +49 1799789624 , claus.nesensohn@refineprojects.com 


\begin{tabular}{|l|l|}
\hline Maturity level & Definition \\
\hline 0-Uncertain & The Ideal Statement is hardly evidenced in action \\
\hline 1-Awakening & General awareness exists and the Ideal Statement is inconsistently evidenced in action \\
\hline 2-Systematic & The Ideal Statement is systemically evidenced in action \\
\hline 3-Integrated & The Ideal Statement is interrelated as a whole and happens automatically \\
\hline 4-Challenging & The Ideal Statement is status quo which is challenged to improve further \\
\hline
\end{tabular}

Figure 1: Definition of the Maturity Levels

They are a powerful and flexible method for understanding the experience of individuals (Fontana and Frey 1994, Kvale 2007). They also enhance the depth and breadth of the phenomenon under investigation, having been seen to be useful for research within the construction sector (Shehu and Akintoye 2010).

The validity was obtained through experts which were involved in the earlier data collection stage to ensure the interpretation of the data was accurate. This research proved the suitability of MM and the LCCM as an appropriate method to measure the current state of maturity and to support organisations in planning and directing their transformation towards greater LC maturity (Nesensohn 2014a).

This paper intends to present the LCMM and its assessment method for its implementation in practice. With that, it will be possible to test and demonstrate the whole range of benefits, and implications of the LCMM.

\section{LC MATURITY ASSESSMENT}

The inputs for any assessment of the LCMM are evidences, observed behaviours, and actions of the organization collected through a maturity assessment (Nesensohn 2014). A two-step maturity assessment procedure has been developed.

The first step is to recollect and analyse all evidence for the current state of LC maturity in the organisation. The second step is a comparison of the gathered evidence against the Ideal Statements and evaluation with the maturity levels. In the Appendix 01 at the end of this paper is presented a template with all the key attributes, behaviour, goals \& practices and their ideal statements to determine the maturity of any organisation that intends to assess and improve their maturity in LC.

This will be done for each key attribute as part of the LCMM to determine a maturity level. This level is calculated by the lowest maturity level assigned amongst all behaviour, goals \& practices within this key attribute as shown in the example within Figure 2.

\begin{tabular}{|l|l|l|r|}
\hline \multicolumn{2}{|l|}{ Lean Leadership } & Their leaders fundamentally own it and have a passion and tenacity about Lean so that they \\
are doing it for themselves. & 3 \\
\hline 1. Passion & A: Their leaders have a true understanding of Lean and see the big picture. & 3 \\
\cline { 2 - 5 } & B: Leaders make decisions with short-term pain to achieve long-term gain. & 4 \\
\cline { 2 - 5 } & 2. True Understanding & $\begin{array}{l}\text { Leaders have a internalised pre-set position that everything can be improved and they apply } \\
\text { it to their own objectives. }\end{array}$ & 3 \\
\cline { 2 - 5 } & 3. Pre-set Position & Their leaders drive, deploy and spread the new behaviour by being the example. & 3 \\
\hline 4. Walk the Talk & All leaders conduct their day in a standard and systemic way. & 2 \\
\hline 5. Standard Work & &
\end{tabular}

Figure 2. LCMM assessment for the Factor - Leadership and the key attribute Lean Leadership 
After that, the overall maturity level can be calculated through the multiplication of the maturity level of each Key Attribute with a weighting factor whose total sum is divided by the total sum of the weighting factors. Each Organisation must weigh the key attributes, which they find most important to them. Nevertheless, there can be no weighting factor with "0" or higher than " 4 ". This will generate a single score from 0-4 for the organisation's total maturity in LC as shown in Figure 3.

\begin{tabular}{|r|l|r|r|r|l|}
\hline No. & Key Attribute & $\begin{array}{l}\text { Initial } \\
\text { Level }\end{array}$ & $\begin{array}{l}\text { Weighting } \\
\text { Factor }\end{array}$ & Result & $\begin{array}{l}\text { Total maturity } \\
\text { level. }\end{array}$ \\
\hline 1 & Lean Leadership & 3 & 4 & 12 & \\
\hline 2 & Customer Focus & 2 & 3 & 6 & \\
\hline 3 & Way of thinking & 2 & 3 & 6 & \\
\hline 4 & Culture \& Behaviour & 1 & 4 & 4 & \\
\hline 5 & Competencies & 2 & 2 & 4 & \\
\hline 6 & Improvements Enablesrs & 0 & 2 & 0 & \\
\hline 7 & Processes \& Tools & 2 & 2 & 4 & \\
\hline 8 & Change & 4 & 2 & 8 & \\
\hline 9 & Work Enviroment & 2 & 2 & 4 & \\
\hline 10 & Business Results & 1 & 1 & 1 & \\
\hline 11 & Training \& Competency & 1 & 2 & 2 & $\mathbf{2}$ \\
\hline \multicolumn{7}{|r|}{ Total: } & 27 & 51 & 1,9 \\
\hline
\end{tabular}

Figure 3. LCMM assessment for Lean Leadership Key Factor

Since the framework identifies strengths and weaknesses in terms of LC maturity within organisations. The assessment above shown in table above illustrates gaps and areas with high and low maturity within the current state of LC maturity. AS the example shows, the assessed organization is mature in terms of Change (initial level 4) but lacks in terms of Improvement Enablers.

To obtain the greatest benefit of the maturity assessment, it is suggested to use the LCMM to guide the transformation efforts, and support decisions towards prioritising planned improvement actions with regards to the key attributes which have been rated lowest within the assessment. The information about a gap within can be used for instance to develop targeted interventions and workshops aimed at improving the maturity of a behaviour, goals and practices in the framework.

After the implementation of the improvement actions a re-assessment with the same model, will enable the organisation to monitor changes and improvements actions to identify achieved maturing and learning.

\section{CONCLUSIONS}

Whilst in many organisational disciplines MM have been tried and tested to measure the current state of maturity in order to enable businesses to direct and plan their move towards greater maturity; there is an absence in AEC companies of such a framework for improvement processes focused on LC.

This paper meets that gap by presenting such a MM together with a developed selfassessment. The MM is labelled the LCMM. The LCMM provides a holistic view of the current state of LC maturity within respect to: lean leadership, customer focus, way of thinking, culture \& behaviour, competencies, improvement enablers, processes \& tools, change, work environment, business results, and learning and competency development. 
In so doing, this LCMM contributes to the body of knowledge in LC in two ways. Firstly, the development of a validated MM provides a verified method to measure the current state of LC maturity in organisations. Secondly, the data collected to inform the development of the LCMM reveals four main phenomena as the essence of maturity in LC. These are: 1) the crucial role of leadership in driving LC maturity, 2) the need to focus on culture and behaviour, 3) the requisite knowledge about Lean, and 4) the low resistance to change.

From a practical perspective, the research provides construction organisations with a method to identify specific strength and weaknesses of LC approaches which can support the planning and directing of transformative LC-based programmes.

Hence, the LCMM highlights gaps in capability, as well as evidence-based support to decision-making in terms of the prioritising of planned improvement actions towards greater LC maturity.

Therefore, the outputs from an assessment using the LCMM can be used to develop targeted interventions. To support such interventions workshops can be held with the aim of improving the maturity of behaviours, goals and practices associated with, specifically, a key attribute and, generally, overall LC maturity.

Finally, it is expected that the LCMM will further 'mature' through its utilisation in practice. This should be considered within a case study-driven research. The author invites organisations within the AEC Industry to test the LCMM and their current maturity and share their experience. Additionally, the generalisation of the emerged explanation of LC maturity as well as the 11 key attributes of LC can be further confirmed or disconfirmed through further empirical evidence.

\section{REFERENCES}

Fontana, A. and J. H. Frey (1994). The art of science. "Handbook of Qualitative Research." N. Denzin and Y. Lincoln. Sage, London, 361-377.

Kvale, S. (2007). "Doing interviews." Sage, London.

Larsson, J., Eriksson, P. E., Olofsson, T. and Simonsson, P. (2013). Industrialized construction in the Swedish infrastructure sector: Core elements and barriers. Construction Management and Economics pp.1-14.

Morse, J. M. (2003). Principles of mixed methods and multimethod research design. Handbook of mixed methods in social \& behavioural research. A. Tashakkori and C. Teddlie. Sage, London, 189-208.

Meiling, J., F. Backlund and H. Johnsson (2012). "Managing for continuous improvement in off-site construction: Evaluation of lean management principles." Engineering, Construction and Architectural Management, 19(2), 141-158.

Nesensohn, C. 2014a. An Innovative Framework For Assessing Lean Construction Maturity. Ph.D., Liverpool John Moores University, (available at http://ethos.bl.uk.

Nesensohn, C., D. Bryde, E. Ochieng, D. Fearon and V. Hackett 2014b. Assessing Lean Construction maturity. In: Proc. 22nd Ann. Conf. of the Int'l. Group for Lean Construction. Oslo, Norway, Aug. 25-27.

Nesensohn, C., Bryde, D., and Pasquire, C., 2015. A measurement model for lean construction maturity. In: Proc. 23rd Ann. Conf. of the Int'l. Group for Lean Construction. Perth, Australia, July 29- 31, pp. 652-660.

Pennypacker, J. S. 2005. Project portfolio management maturity model. Pennsylvania: Center for Business Practices. 
Perkins, L. N., L. Abdimomunova, R. Valerdi, T. Shields and D. Nightingale (2010a). "Insights from enterprise assessment: How to analyze LESAT results for enterprise transformation. "Information Knowledge Systems Management, 9(3/4), 153-174.

Perkins, L. N., L. A. Initiative, R. Valerdi, D. Nightingale and S. Rifkin (2010b). Organizational assessment models for enterprise transformation. Proceedings of INCOSE International Symposium. Chicago, USA.

Sage, D., A. Dainty and N. Brookes (2012). "A 'strategy-as-practice' exploration of Lean construction strategizing." Building Research \& Information, 40(2), 221-230.

Shehu, Z. and A. Akintoye (2010). "Major challenges to the successful implementation and practice of programme management in the construction environment: A critical analysis. "International Journal of Project Management, 28(1), 26-39.

Smithson, J. (2008). Focus Groups. "The Sage Handbook of Social Research Methods." P. Alasuutari, L. Bickman and J. Brannen. Sage, London, 356-371. 


\section{APPENDIX - - ASSESSMENT GRID OF THE LCMM}

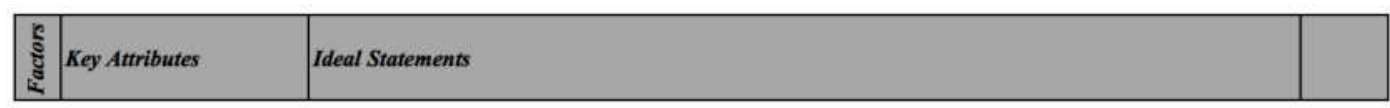

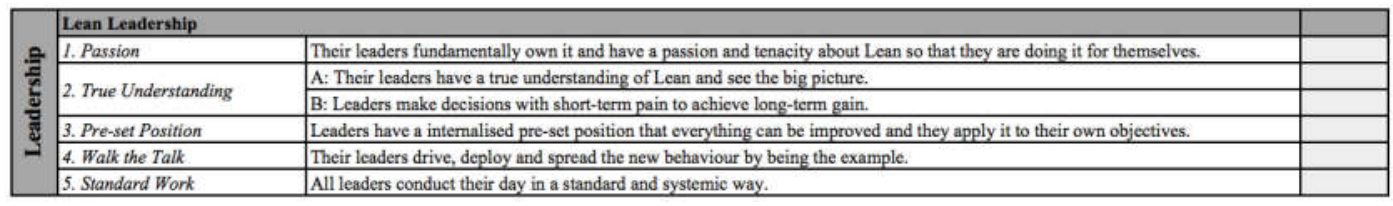

\begin{tabular}{|c|c|c|}
\hline \multirow{15}{*}{ 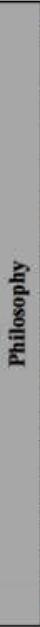 } & \multicolumn{2}{|l|}{ Customer Focus } \\
\hline & \multirow{3}{*}{$\begin{array}{l}\text { 1. Understanding Customer } \\
\text { Value }\end{array}$} & $\begin{array}{l}\text { A: They understand that customer value involves the requirements of the chain of internal and external customers up to the end } \\
\text { user. }\end{array}$ \\
\hline & & B: It is accepted that customer value can be intangible and the value of customer $A$ can be the waste for customer B. \\
\hline & & $\begin{array}{l}\text { C: They are focused on the value perception of the chain of customers to be elear what is the required value that needs to be } \\
\text { delivered in the best possible way. }\end{array}$ \\
\hline & \multirow{2}{*}{$\begin{array}{l}\text { 2. Identifying Ultimate } \\
\text { Customer Value }\end{array}$} & A: They are outstanding in identifying real value for their customens. \\
\hline & & $\begin{array}{l}\text { B: They actively revise the identified value stream to react to any changes of the customer value and to tackle any waste in this } \\
\text { sequenoc of processes to create the ultimate valuc. }\end{array}$ \\
\hline & 3. Value Monitoring & They know their deviation from the customer value by monitoring the effectiveness of delivering this value. \\
\hline & 4. Being "Customer Driven" & $\begin{array}{l}\text { Leaders and managers focus on doing the best work for the customer and accept that being customer driven is no contradiction to } \\
\text { the business driver such as satisfaction of the shareholders. }\end{array}$ \\
\hline & \multicolumn{2}{|l|}{ Way of Thinking } \\
\hline & 1. Systemic Thinking & $\begin{array}{l}\text { They think systemically to see the big picture, the whole, the information flow within the system and establish links between every } \\
\text { value stream and aspect of the business to create synergies. For example: they practise continuous improvement to see processes } \\
\text { and customers in a systemic way. }\end{array}$ \\
\hline & 2. Process Thinking & The people accept that value is created through processes and understand those processes and their relationships. \\
\hline & 3. Scientific Thinking & $\begin{array}{l}\text { They are rigorous in collecting information about variables to support the decision-making process and testing hypotheses in a } \\
\text { scientific way. }\end{array}$ \\
\hline & 4. Long-Term Thinking & They practice long-term thinking while they aceept pain in short-term decisions, to not affect the long-term goal. \\
\hline & 5. Thinking Teams & $\begin{array}{l}\text { Everybody's activity is aligned in a direction of delivering improvement and challenging processes, from the top to the bottom } \\
\text { regardless of the subject, department or processes. }\end{array}$ \\
\hline & 6. Out-of-the-Bax Thinking & $\begin{array}{l}\text { There are some lateral thinkers who often go off the beaten tracks to find new solutions and challenge the leadership to deliver } \\
\text { improvement. }\end{array}$ \\
\hline
\end{tabular}

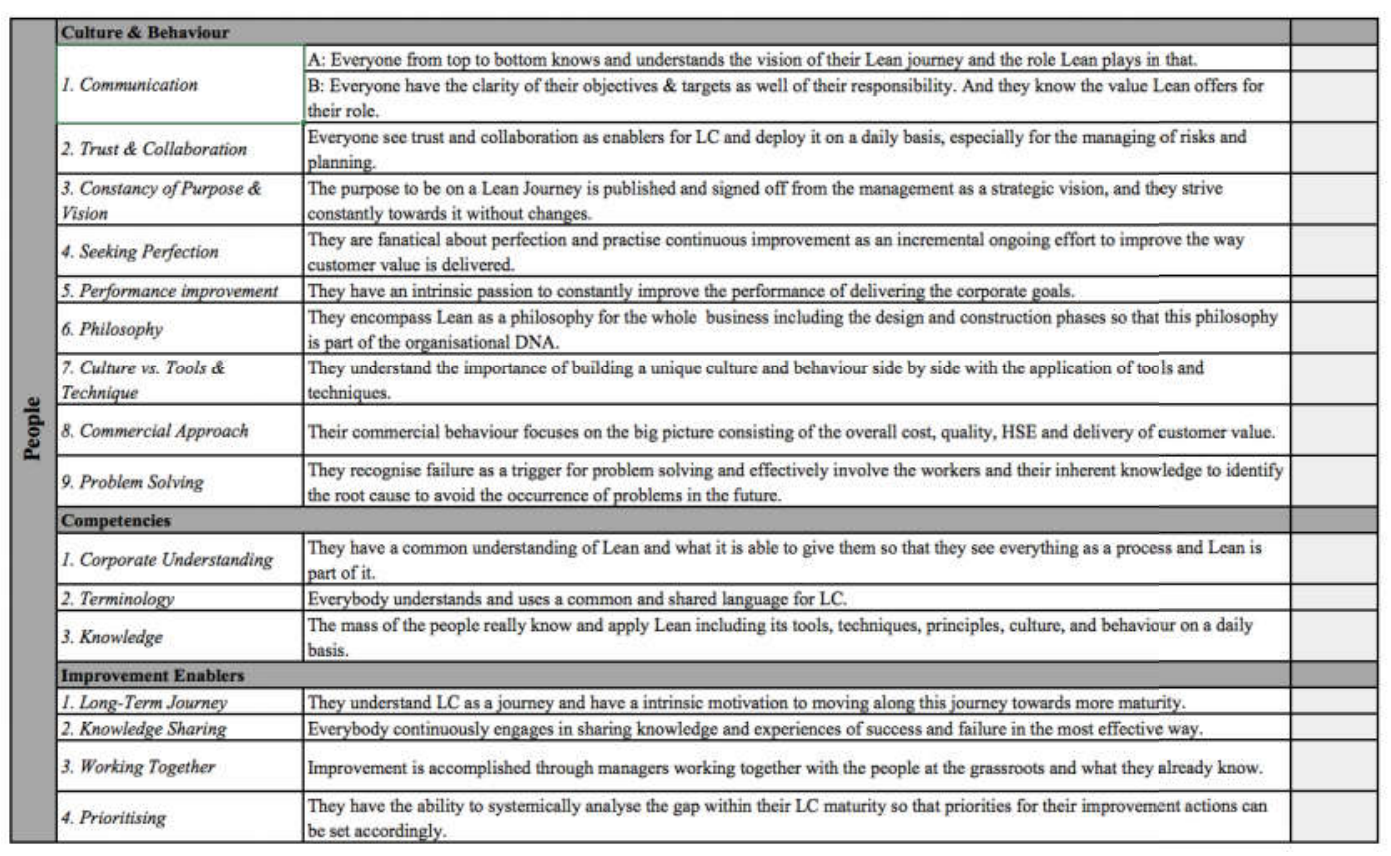




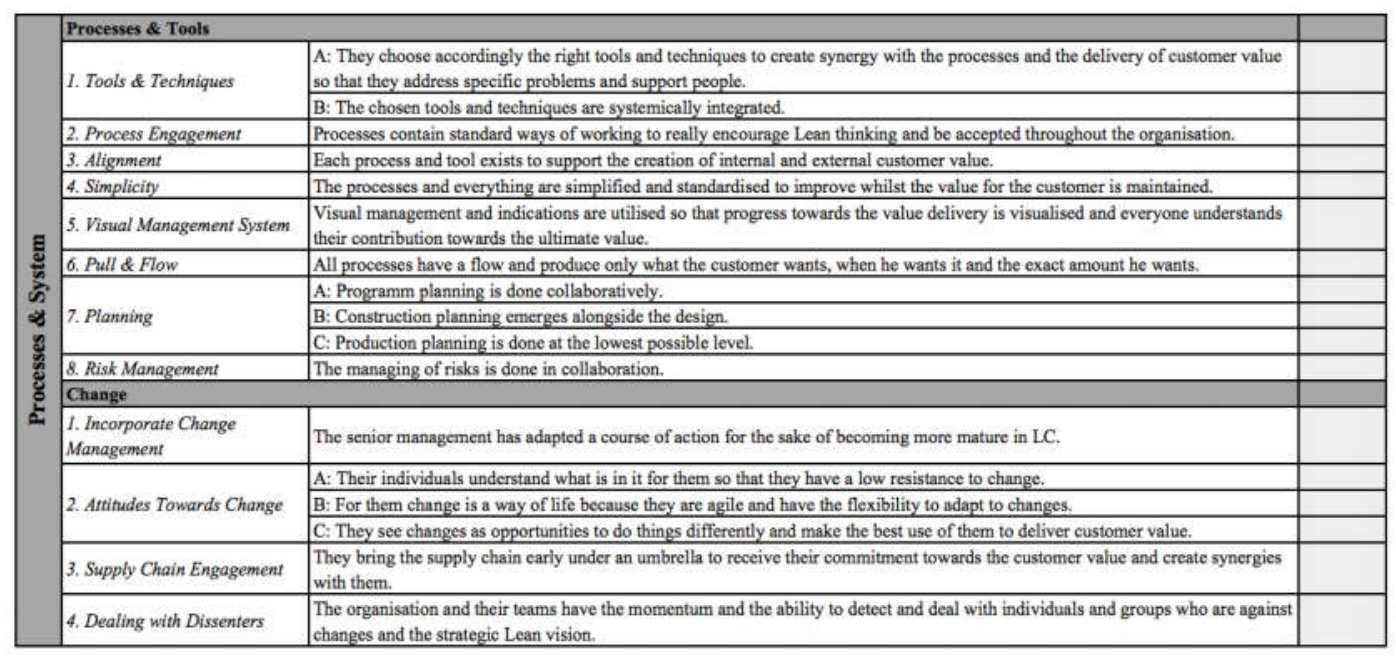

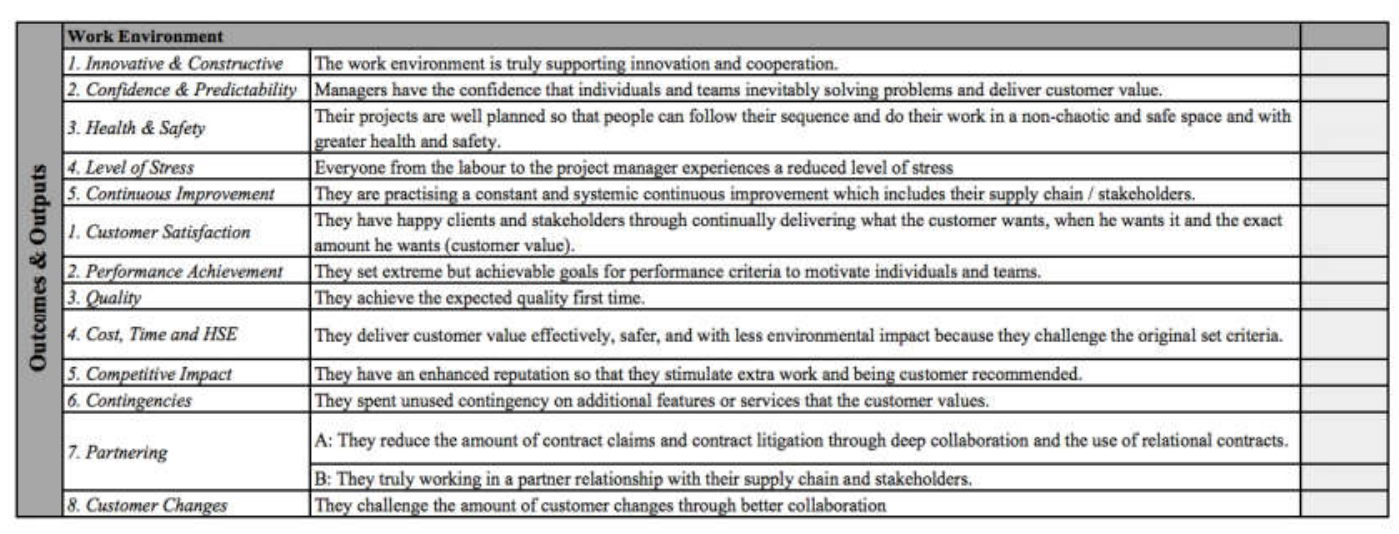

\begin{tabular}{|c|c|c|}
\hline \multirow{9}{*}{ 을 } & \multicolumn{2}{|c|}{ Learning and Competency Development } \\
\hline & \multirow{5}{*}{ 2. Organisational Learning } & $\begin{array}{l}\text { A: They consistently demonstrate a focus on learning of individuals and really utilise lessons leamed as fundamental for practising } \\
\text { continuous improvement. }\end{array}$ \\
\hline & & B: They have a structured approach regarding what they want to achieve with their learning. \\
\hline & & A: They conduct experiments to learn from failure and success. \\
\hline & & B: They have a commitment to unlearning knowledge and openness to the outside world and a mechanism for renewal themselves. \\
\hline & & C: They effectively utilise what the organisation has learned. \\
\hline & 3. Development of People & A: Their leaders develop the people through coaching, mentoring and the delivery of internal training. \\
\hline & \multirow[t]{2}{*}{ 4. Training } & $\begin{array}{l}\text { A: Training focuses on specific ways of working within the processes so that the developed competencies can be applied } \\
\text { effectively. }\end{array}$ \\
\hline & & B: They train new people according to a plan so that they take on their specific eulture in an effective way. \\
\hline
\end{tabular}

